\title{
The Implementation of a 2/4/8 Antennas Configurable Diversity OFDM Receiver for Mobile HDTV Application
}

\author{
Jing Gao, ${ }^{1}$ Takashi Iida, ${ }^{2}$ Hiroyuki Mizutani, ${ }^{3}$ Sadanori Sakaguchi, ${ }^{3}$ \\ Shuji Murakami, ${ }^{3}$ Atsushi Shimizu, ${ }^{2}$ and Tomohisa Wada ${ }^{1,3}$ \\ ${ }^{1}$ Graduate School of Engineering and Science, University of the Ryukyus, Okinawa 903-0213, Japan \\ ${ }^{2}$ Automotive Information Systems Department, SANYO Electric Co., Ltd., Osaka 570-8677, Japan \\ ${ }^{3}$ Development-I, Magna Design Net, Inc, Okinawa 901-0155, Japan
}

Correspondence should be addressed to Jing Gao, gaojing722@yahoo.com

Received 1 February 2009; Accepted 7 October 2009

Recommended by Robert Briskman

Two pre-FFT adaptive array (AA) antenna combiners and a post-FFT carrier diversity (CD) combiner are integrated with a Japan Terrestrial digital TV (ISDB-T) OFDM receiver using $90 \mathrm{~nm} 7 \mathrm{M} 1 \mathrm{P}$ CMOS process. A 2/4/8-antenna diversity receiver can be configured and a low-cost 4 antenna diversity reception system can be realized in one LSI by making use of the AA-CD two-stage diversity combining method. Mobile reception performance is increased by 1.63 times using a denoise filter circuit and SPLINE interpolator under urban 6-path Rayleigh fading (TU6) model with 2-antenna post-FFT carrier diversity (2CD) combing mode. The die area is $49 \mathrm{~mm}^{2}$ and the power consumption is $310 \mathrm{~mW}$.

Copyright () 2009 Jing Gao et al. This is an open access article distributed under the Creative Commons Attribution License, which permits unrestricted use, distribution, and reproduction in any medium, provided the original work is properly cited.

\section{Introduction}

TV broadcasting technology is rapidly shifting to the digital domain and the services are expanding not only to home TV but also to ubiquitous devices such as cellar phones, PCs, and automotive TVs. Orthogonal Frequency Division Multiplexing (OFDM) is adopted as a modulation method for the terrestrial Integrated Services Digital Broadcasting(ISDB-T) standard in Japan. OFDM is wellknown as a high-spectral efficiency transmission method in a multipath environment $[1]$.

When an OFDM receiver is used in an automobile, the Radio Frequency (RF) signal experiences a Doppler frequency shift as the automobile is moving as shown in Figure 1. The Doppler shift destroys the orthogonality between OFDM subcarrier signals and increases intercarrier interference (ICI). Therefore, it is a severe challenge to maintain the reception quality for a mobile ISDB-T receiver that is acceptable for human vision.

One well-known way to improve the performance of an OFDM receiver is to exploit spatial diversity by utilizing multiple antenna elements. In this paper, a mobile OFDM receiver LSI is described which includes two pre-FFT adaptive array (AA) antenna combiners and a post-FFT carrier diversity (CD) combiner. Using the LSI, several combinations of AA and CD diversity systems can be used to tradeoff performance of the mobile ISDB-T receiver with system cost. Additionally, directional antenna elements can be utilized to mitigate the Doppler shift. The performance of the proposed AA-CD scheme is evaluated by simulation and is validated in laboratory and field experiments.

The rest of the paper is organized as follows. In Section 2, diversity receiver fundamentals are explained. The LSI chip architecture and circuits will be described in Sections 3 and 4 , respectively. In Sections 5 and 6 , simulation results and measurement results including field experiments will be shown. Finally, conclusions are given in Section 7.

\section{Diversity Receiver Fundamentals}

2.1. Use of Directional Antenna. Doppler shift $\left(f_{d}\right)$ is given as

$$
\begin{aligned}
f_{d} & =\frac{v}{c} f_{c} \cos (\theta) \\
& =f_{d \max } \cos (\theta),
\end{aligned}
$$



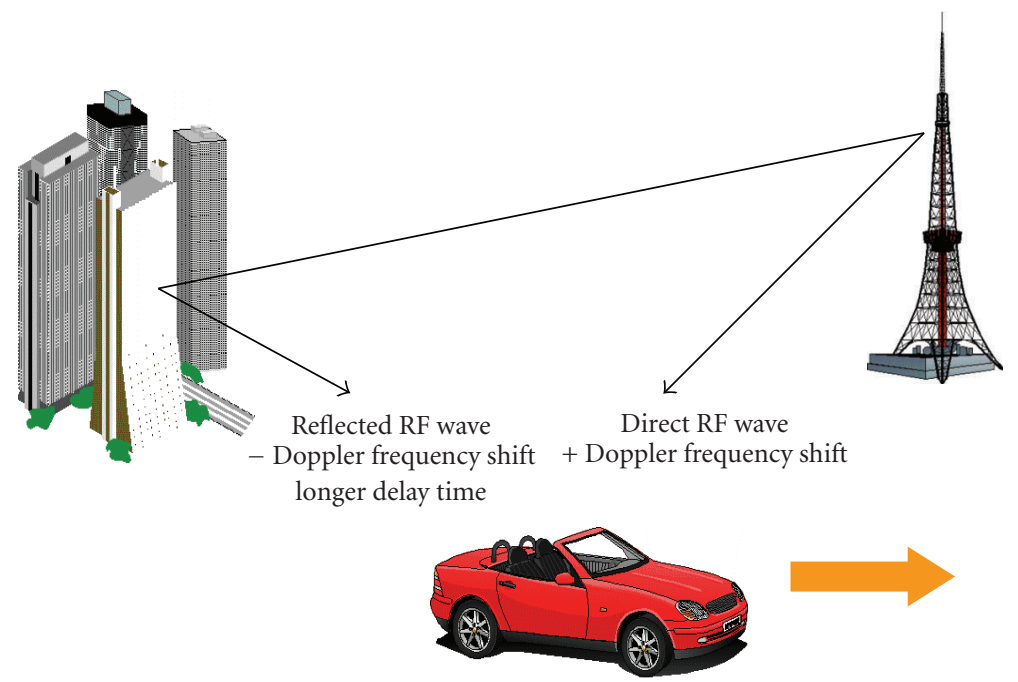

Figure 1: Problems in mobile reception.

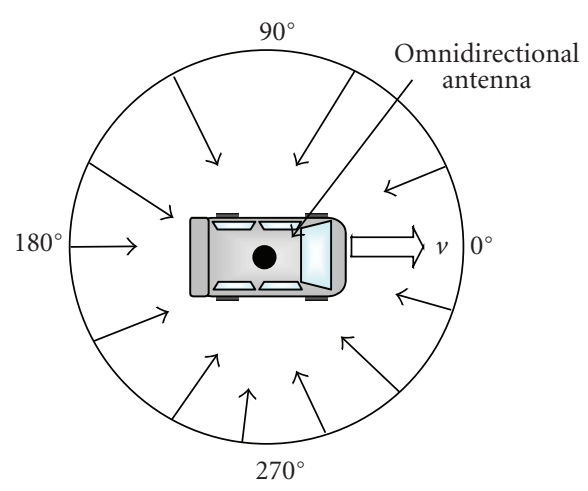

(a)

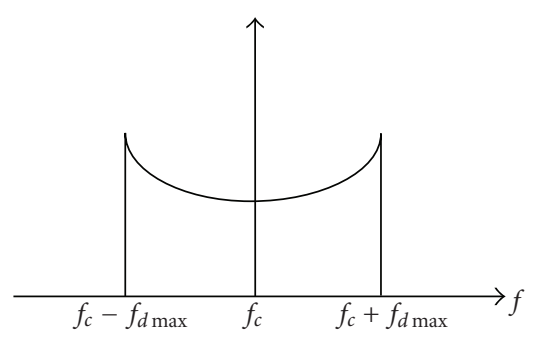

(b)

FIGURE 2: Doppler frequency shift for omnidirectional antenna. (a): In coming RF waves, (b): Doppler frequency distribution.

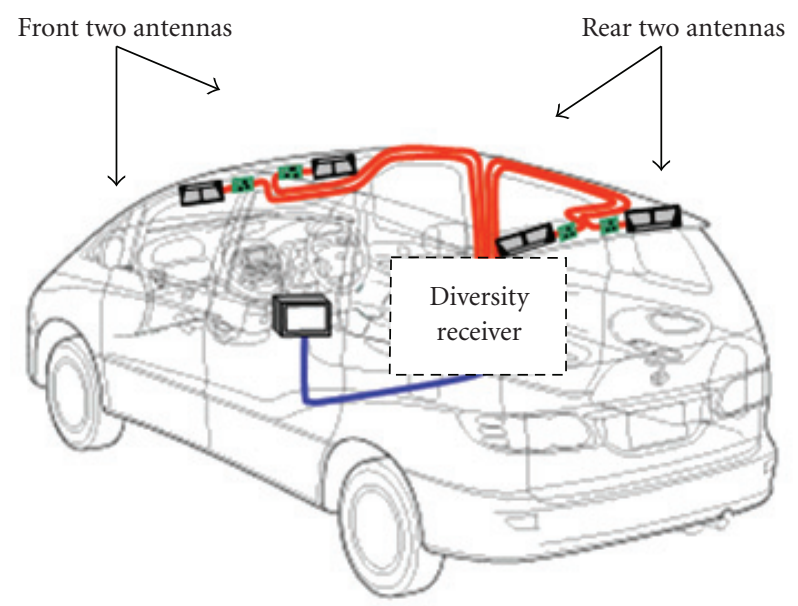

Figure 3: Antennas on vehicle.

where $v$ and $c$ are speed of the automobile and light, respectively, $f_{c}$ is the carrier frequency, and $\theta$ is the Angle of Arrival (AOA) of the incoming signal. The maximum Doppler shift is determined as $f_{d \max }=(v / c) f_{c}$. When an automobile has one omnidirectional antenna on the roof as shown in Figure 2(a), the antenna receives all directional incoming RF waves, which is uniformly distributed within $[0,2 \pi]$. The spectrum of the received signal is distributed over $\left[f_{c}-f_{d \max }, f_{c}+f_{d \max }\right]$ as shown in Figure 2(b).

Figure 3 shows a typical 4 space diversity antenna configuration for an automobile. Two antenna elements are set in the front and the two are set in the rear. However as the body of the automobile is made from metal, the two front antenna elements seemingly experience a similar Doppler shift, as do the two in the rear. It has been experimentally confirmed that the directional characteristic of the front antenna is obviously distorted and concentrates in the forward direction, while the rear antenna focuses to the rear direction of automobile [2]. Consequently, as illustrated in Figure 4, the received signal from the front antenna element predominantly experiences a positive Doppler shift randomly distributed within $\left[f_{c}, f_{c}+\right.$ $\left.f_{d \max }\right]$ while that of rear antenna element predominantly experiences a negative Doppler shift randomly distributed 


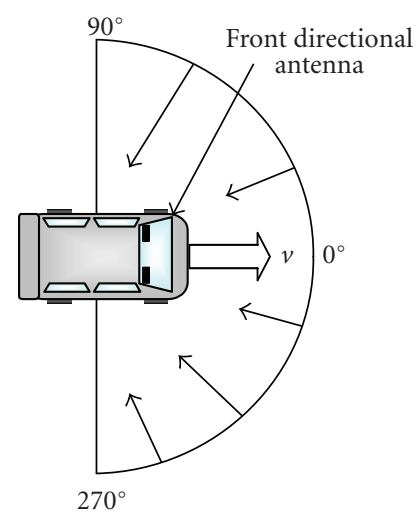

(a)

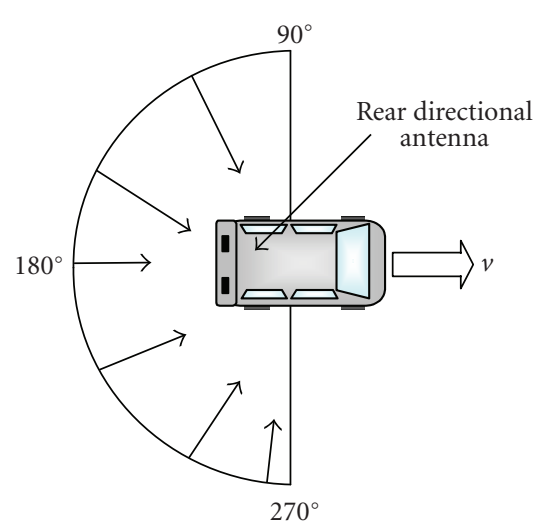

(c)

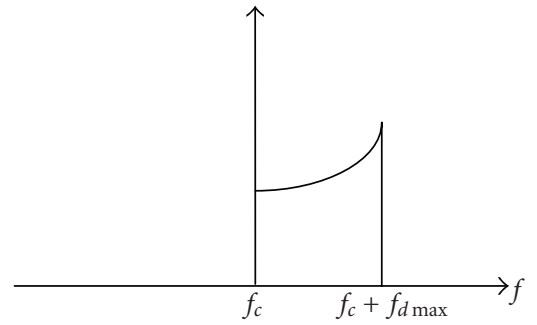

(b)

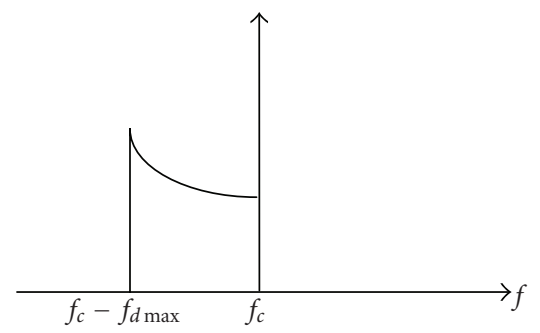

(d)

Figure 4: Doppler frequency shift for front and rear directional antenna: (a) and (b) front directional antenna; (c) and (d) rear directional antenna.

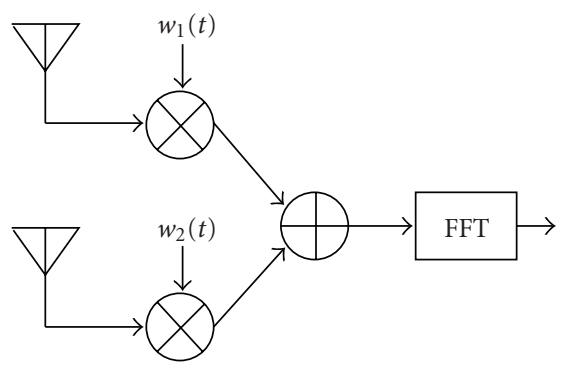

(a)

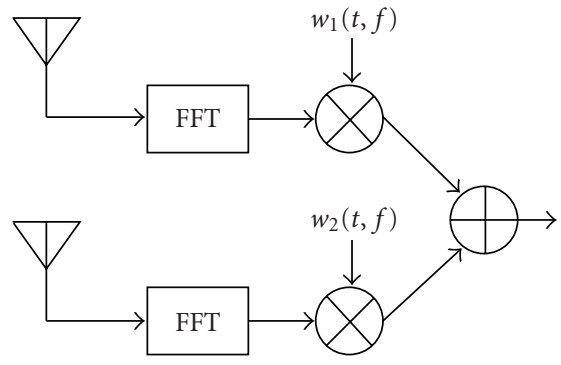

(b)

FIGURE 5: Two diversity combining methods. (a): pre-FFT adaptive array (AA) antenna, (b): post-FFT carrier diversity (CD).

within $\left[f_{c}-f_{d \max }, f_{c}\right]$. In other words, the performance of a mobile ISDB-T receiver is seemingly enhanced as the bandwidth of the Doppler spectrum is reduced by exploiting directional antenna elements.

2.2. Two Types of Diversity Combining Methods. There are two approaches to utilize the array antenna for multicarrier transmission: pre-FFT adaptive array (AA) antenna and post-FFT carrier diversity (CD) combining.

As shown in Figure 5(a), the AA scheme is a conventional method to employ the array antenna in which inputs from the array antenna are combined before OFDM demodulation [3-5]. Since this approach uses one set of coefficients such as $w_{i}(t)(i=1,2)$ for each OFDM symbol, it is an attractive solution due to low computation complexity. However, for good performance, received antenna signals should have high correlation.

On the other hand, the post-FFT scheme is an advanced method to utilize the array antenna for a multi-carrier system as shown in Figure 5(b). Instead of combining before OFDM demodulation, inputs are demodulated using multiple OFDM demodulations. Subcarriers are then combined accordingly in the frequency domain using the diversity 


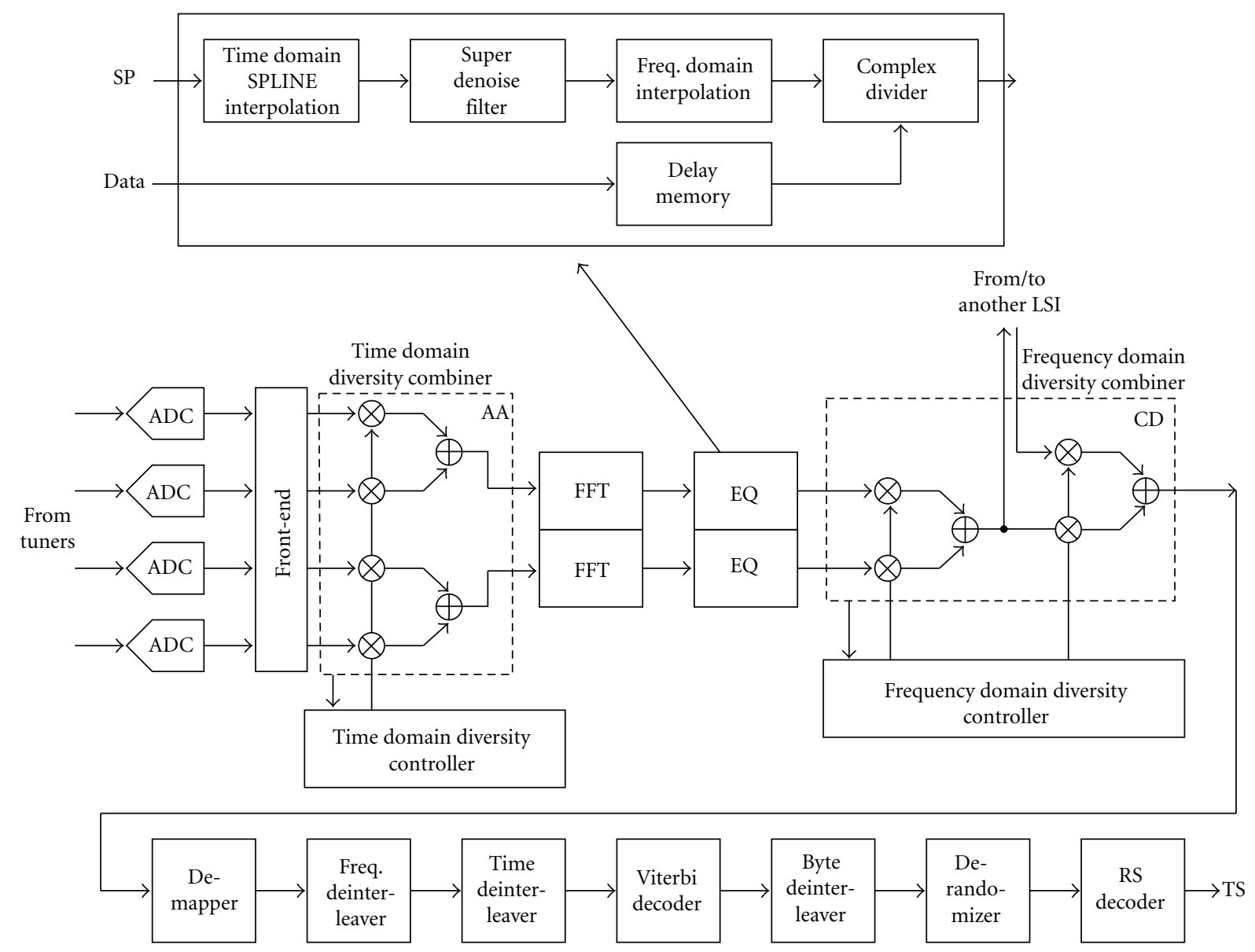

Figure 6: Detailed block diagram of receiver.

TABLE 1: Features of two diversity methods.

\begin{tabular}{llll}
\hline Type & Circuit & Performance & Restriction \\
\hline $\begin{array}{l}\text { Adaptive Array } \\
\text { (AA) }\end{array}$ & Small & Moderate & $\begin{array}{l}\text { High antenna } \\
\text { signal correlation }\end{array}$ \\
Carrier Diversity & Large & High & None \\
\hline
\end{tabular}

combining method [6]. The Post-FFT scheme therefore is an optimum approach in term of maximizing signal-tonoise ratio (SNR) for each OFDM subcarrier. However, its computation complexity grows drastically as the number of antenna elements increases. The characteristics of the two diversity methods are summarized in Table 1.

\section{Chip Architecture}

Figure 6 shows the detailed block diagram of the receiver LSI. The UHF wireless signal is down-converted by tuners. A maximum of 4 tuner output signals are fed into one LSI and are converted to digital signals by ADCs. The first AA stage performs the array antenna signal processing and the second CD stage combines each OFDM subcarrier signal at the output of the Fast Fourier Transforms (FFT)/equalizers (EQ) processing. The two-stage diversity combiners halve the number of FFT/EQ circuits from 4 to 2 but maintain equivalent mobile reception performance compared to the 4 FFT/EQs case. The number of logic gates is reduced by $39 \%$ through the using of the two-stage architecture. To improve higher mobile performance, the equalizer introduces two new circuit blocks, the SPLINE interpolator and the super denoise filter, which will be explained in the following section.

4 types of diversity configurations are possible as shown in Figure 7. With each doubling of the number of antennas, SNR is improved by approximately $3 \mathrm{~dB}$. For the 4 -antenna case, there are two possible configurations. The 4AA mode is a one-chip solution that achieves the lowest cost and modest performance. The 4CD mode is a two-chip solution with higher performance. Since the antenna placement on a car is usually on the front or rear windshield glass, each antenna has directional gain fluctuation due to the car body. The 4antenna system is preferable for compact to medium size cars to cover all signal angles of arrival.

\section{Circuits}

4.1. SPLINE Time Domain Interpolator. Figure 8 shows the newly introduced SPLINE interpolator. The subcarrier signals (see left) of FFT output are divided into two parts, 

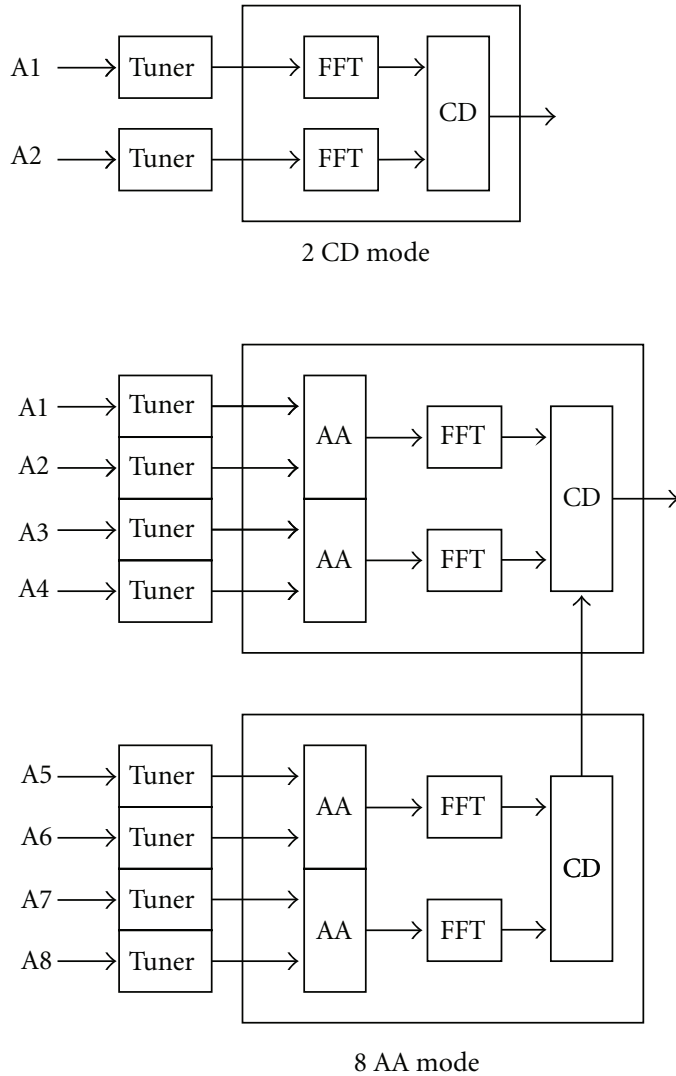

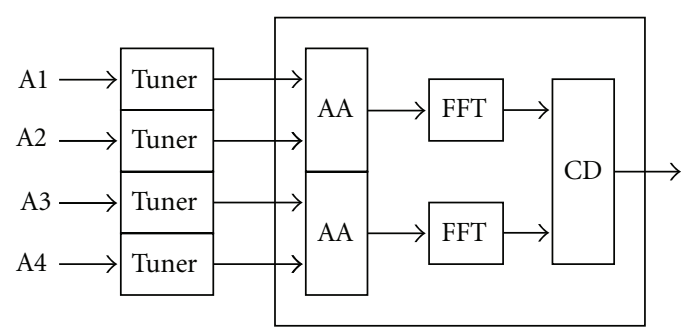

4 AA mode (low cost)

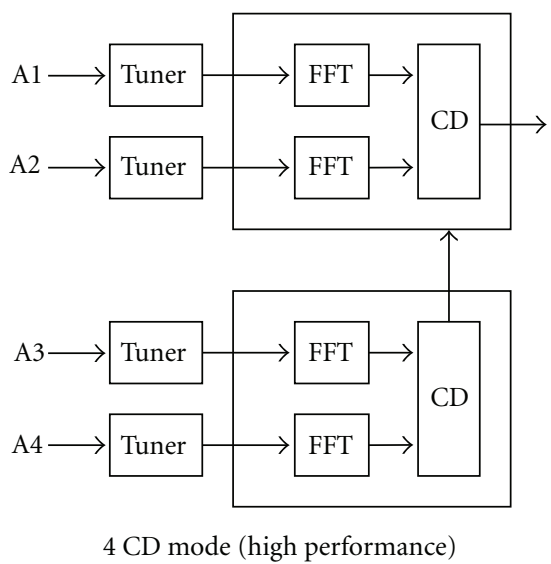

FIgURE 7: 2/4/8 antennas system configurations.

TABLE 2: Coefficients of 4-tap SPLINE FIR filter.

\begin{tabular}{ccccc}
\hline & C1 & C2 & C3 & C4 \\
\hline 11 & $1 / 64$ & $-6 / 64$ & $25 / 64$ & $44 / 64$ \\
12 & $1 / 40$ & $-6 / 40$ & $29 / 40$ & $16 / 40$ \\
13 & $7 / 320$ & $-42 / 320$ & $303 / 320$ & $52 / 320$ \\
\hline
\end{tabular}

data (white circle) and scattered pilots (SPs, circle with P). Those SPs are located every 12 subcarriers in one OFDM symbol and the position of the SP shifts by 3 subcarriers every OFDM symbol. In previous work [7], 2-tap linear interpolation is performed by the two SPs in the linear interpolation zone. In this paper, the new SPLINE algorithm 4-tap interpolation is applied. Although the SPLINE uses two more past SPs in the SPLINE interpolation zone (total 4 taps), the 3 symbols of filter latency (see symbol number $=-3)$ is the same as the previous work. Then the higher interpolation accuracy is obtained without increasing the delay RAM size in the equalizer.

The 4-tap FIR filter is implemented using a poly-phase accumulator. Figure 9 shows a logical view of the 4-tap polyphase FIR filter. The position of the I1, I2, and I3 points can be computed by changing the filter coefficients of $\mathrm{C} 1$, $\mathrm{C} 2, \mathrm{C} 3$, and C4. Those coefficients are computed using the mathematical SPLINE function. Actual coefficients of the 4tap SPLINE FIR filter are shown in Table 2.
4.2. Variable Bandwidth Super Denoise Filter. To reduce noise on the interpolated SP signals further, a variable bandwidth complex bandpass filter is introduced. The bandwidth and the center frequency are controlled by a delay-profile of the reception signal. To support fine control of the center frequency and a broad range of filter bandwidth, a twostage serially connected circuit is used as shown in Figure 10. Both stages are identical 41-tap raised cosine Lowpass Filters (LPF). The bandpass position of each stage can be shifted using the complex rotation circuit, that is, complex multiplier at each input/output. Through the combination of the two stages, the complex filter bandwidth and center frequency can be controlled. The upper section of Figure 10 shows the example of a 1/4 bandwidth LPF. The shaded area is the complex bandpass filter bandwidth.

\section{Simulation Results}

In this section, the 4 operation modes (shown in Figure 7 above) $2 \mathrm{CD}, 4 \mathrm{AA}, 4 \mathrm{CD}$, and $8 \mathrm{AA}$ are verified by computer simulation. To evaluate performance, directional characteristics of antenna elements are modeled based on [8]. Table 3 shows the system parameters. Mode 3 of the ISDB$\mathrm{T}$ standard using 64QAM modulation and Guard Interval (GI) duration $T_{g}=T_{e} / 8$ is used for the simulation. Bit Error Rate (BER) is measured without Error correction. Table 4 shows the specification of the simulation parameters. 


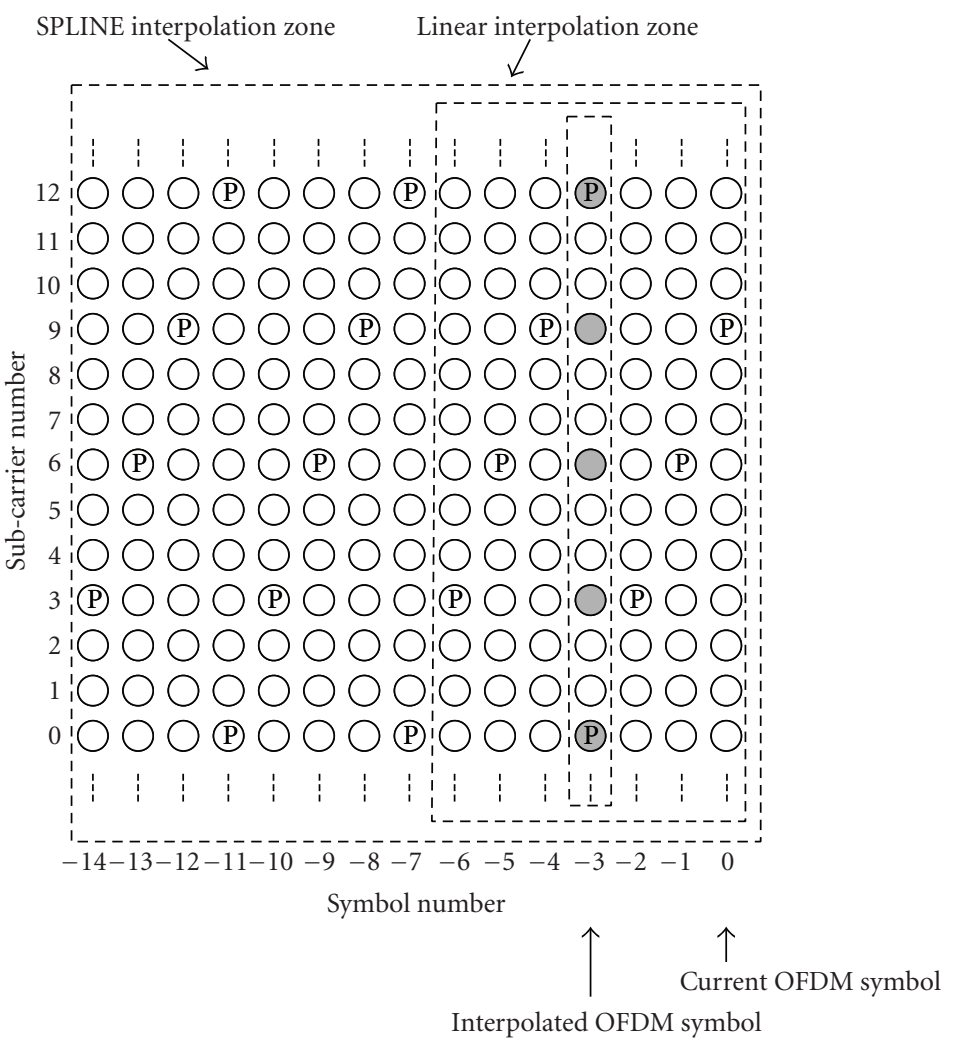

(a)

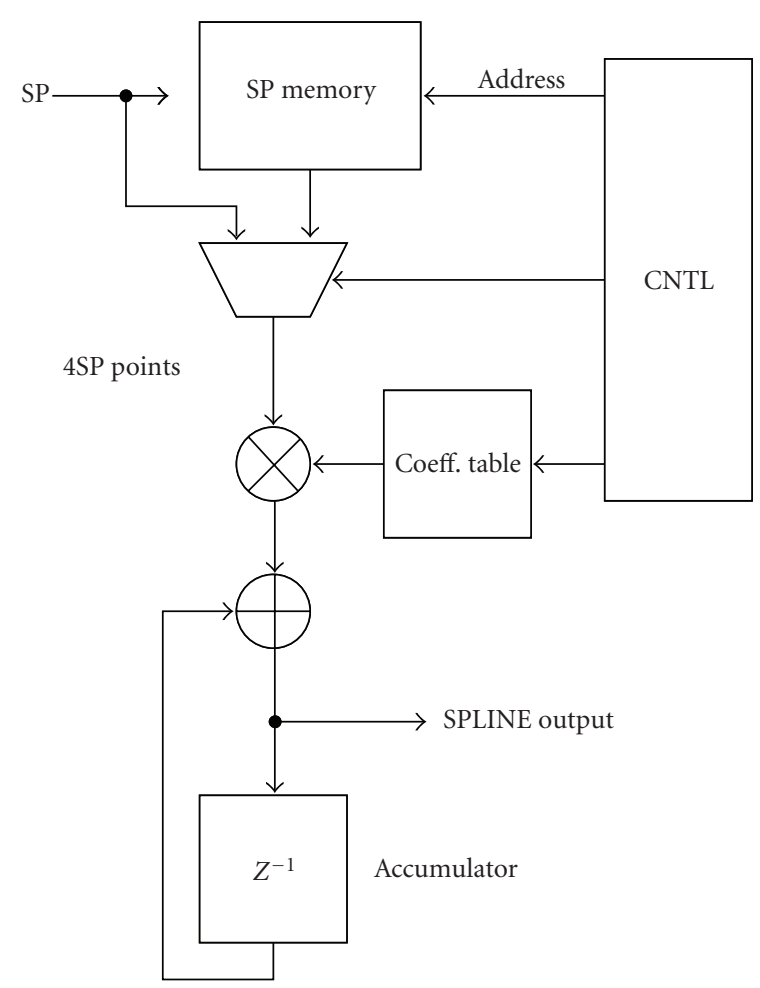

(b)

FIGURE 8: SPLINE time domain interpolator.

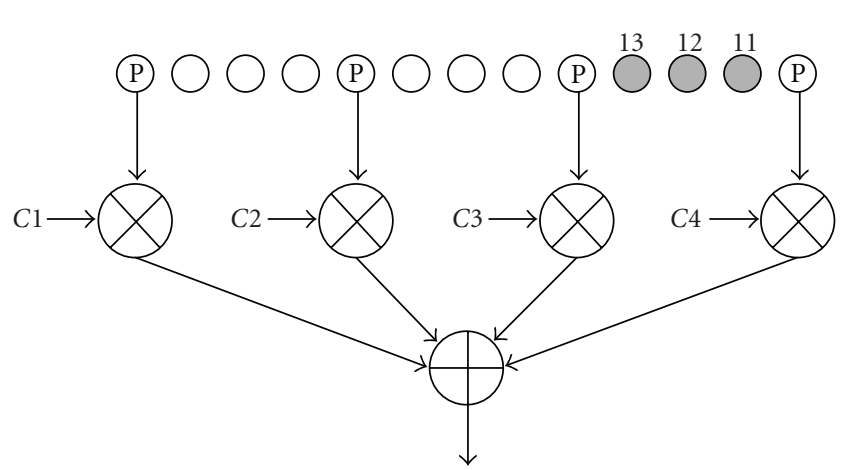

$13 \quad 12 \quad 11$

FIGURE 9: 4-tap FIR filter for SPLINE interpolation.

TABLE 3: OFDM system parameters.

\begin{tabular}{lc}
\hline \multicolumn{2}{c}{ System Parameters } \\
\hline Carrier Frequency & $563.143 \mathrm{MHZ}$ \\
FFT size & 8192 \\
Number of used subcarrier & 5167 \\
Effective Symbol Duration & $\mathrm{Te}=1008 \mathrm{us}$ \\
Guard Interval Duration & $\mathrm{Tg}=\mathrm{Te} / 8$ \\
Digital Modulation & $64 \mathrm{QAM}$ \\
\hline
\end{tabular}

6 signals are received with different power and delay time. Since signal 2 at 30 degrees is the strongest, it is considered
TABLE 4: 6-path simulation parameters.

\begin{tabular}{lccc}
\hline Path & Angle $(\mathrm{deg})$ & $\mathrm{D} / \mathrm{U}(\mathrm{dB})$ & Delay \\
\hline 1 & 0 & 5 & $0.5 *(\mathrm{Tg} / 8)$ \\
2 & 30 & 0 & 0 \\
3 & 90 & 8 & $3.2 *(\mathrm{Tg} / 8)$ \\
4 & 150 & 6 & $2.5 *(\mathrm{Tg} / 8)$ \\
5 & 210 & 1 & $0.3 *(\mathrm{Tg} / 8)$ \\
6 & 300 & 7 & $4.0 *(\mathrm{Tg} / 8)$ \\
\hline
\end{tabular}

TABle 5: Summary of die.

\begin{tabular}{lc}
\hline Process Technology & $90 \mathrm{~nm} 7 \mathrm{M} 1 \mathrm{P}$ CMOS \\
\hline Logic & $1.8 \mathrm{M}$ gates \\
Memory and ADC & $18.4 \mathrm{M} \mathrm{bit} / 4 \mathrm{ADC}$ \\
Supply Voltage & $1.2 \mathrm{~V} \mathrm{core,} 3.3 \mathrm{~V} \mathrm{I} / \mathrm{O}$ \\
Active Power & $310 \mathrm{~mW}$ typical \\
Die Size & $7.0 \mathrm{~mm} \times 7.0 \mathrm{~mm}$ \\
Package & $12 \mathrm{~mm} \times 12 \mathrm{~mm}$ \\
& $144 \mathrm{FBGA}$ \\
\hline
\end{tabular}

the desired signal while the others are considered undesired signals. The DU ratio $(\mathrm{D} / \mathrm{U})$ is the Desired to Undesired signal power ratio. Signal 1 at 0 degree is $5 \mathrm{~dB}$ lower power than 2. 

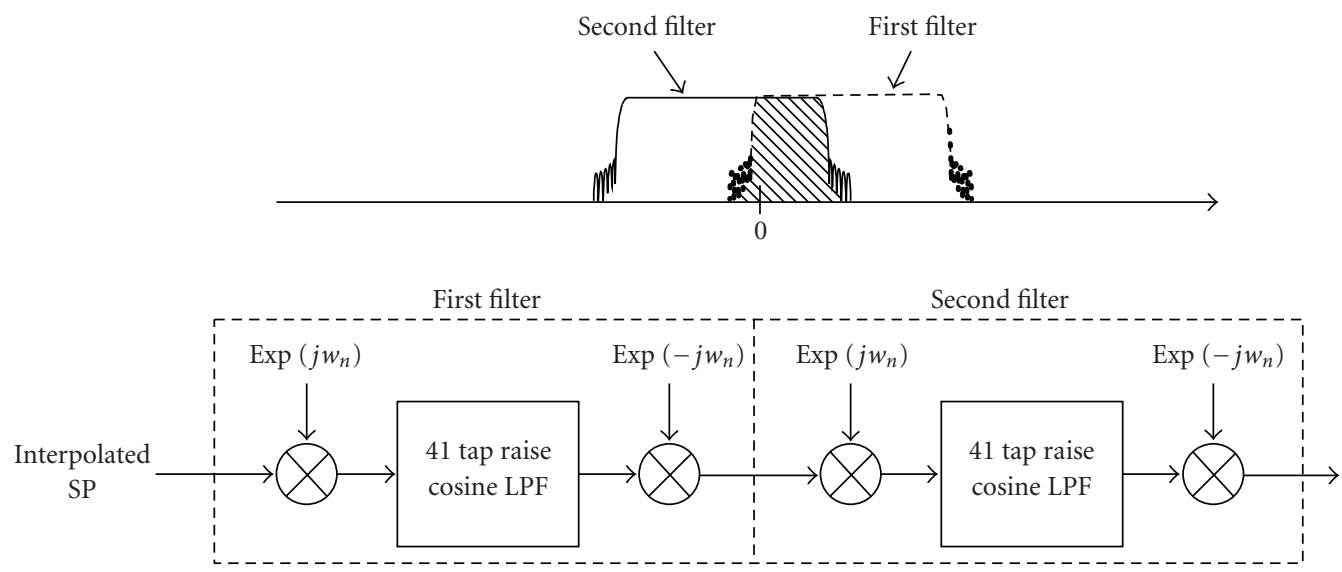

FIgURE 10: Variable bandwidth super denoise filter.

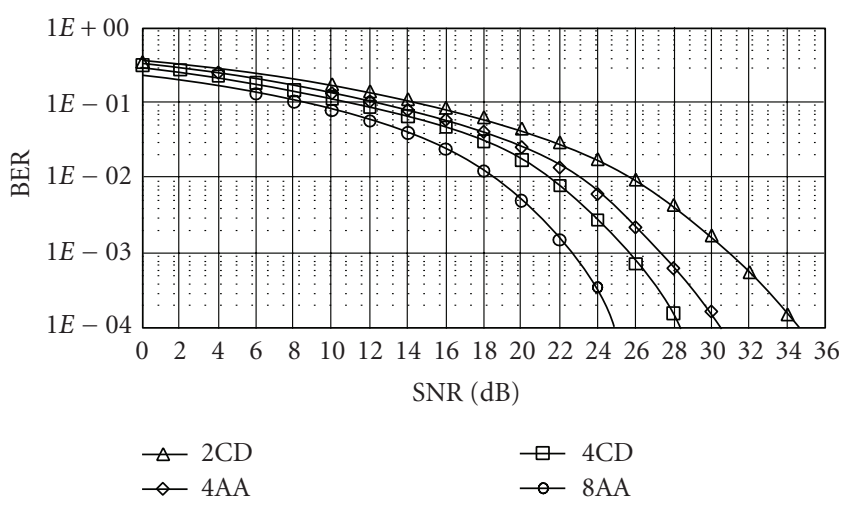

FIgURE 11: BER versus SNR with Doppler shift of $0 \mathrm{~Hz}$.

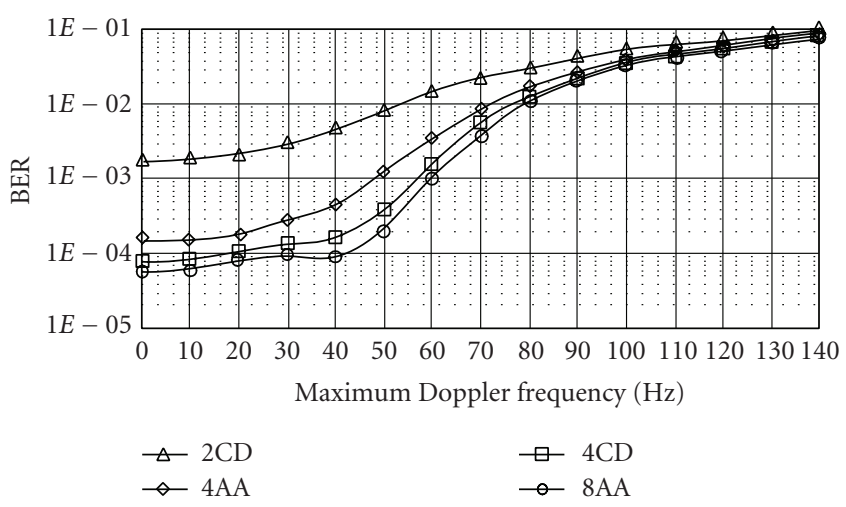

FIGURE 12: BER versus Maximum Doppler shift with SNR $=30 \mathrm{~dB}$.

Figure 11 shows BER performances versus SNR with Doppler shift $=0 \mathrm{~Hz}$. BER performance improves with increasing number of antenna elements. $4 \mathrm{CD}$ shows slightly better performance than 4AA. In addition, BER performances versus Maximum Doppler shift with SNR of $30 \mathrm{~dB}$ are shown in Figure 12. Moving from 2CD to the other modes, there are significant Doppler performance improvements. 2CD only uses 2 front antennas and the other modes

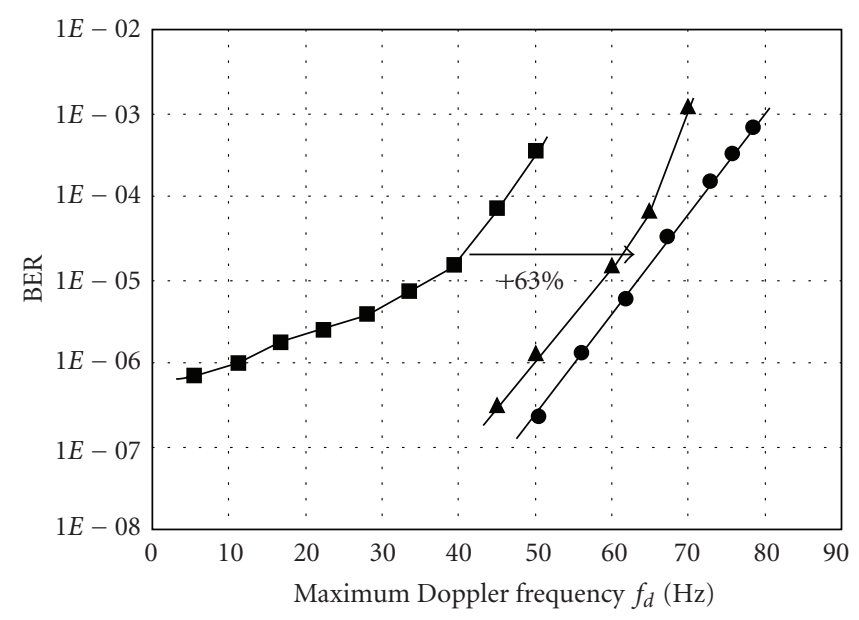

- Previous work linear

ム SPLINE only

- This work SPLINE + denoise

Figure 13: Mobile reception performance comparison of $2 \mathrm{CD}$ mode.

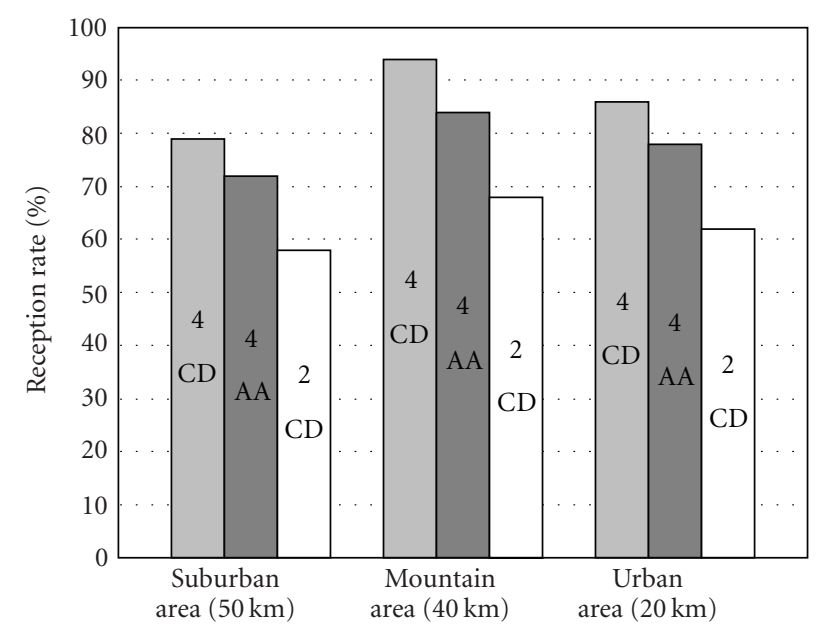

FIGURE 14: Field experimental result. 


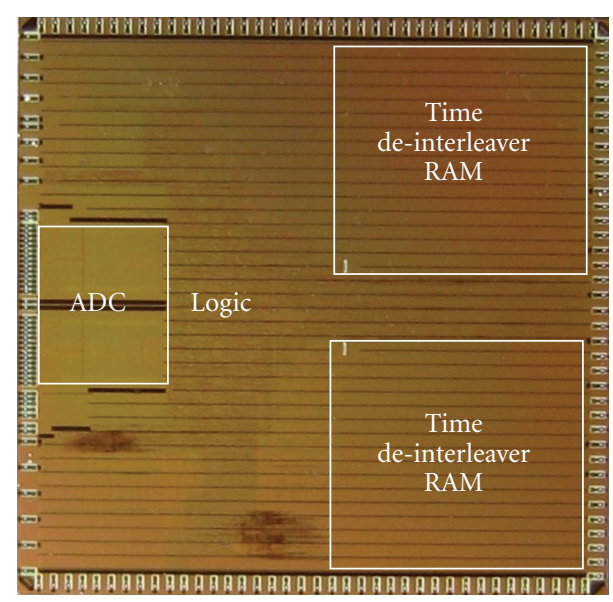

FIGURE 15: Die micrograph.

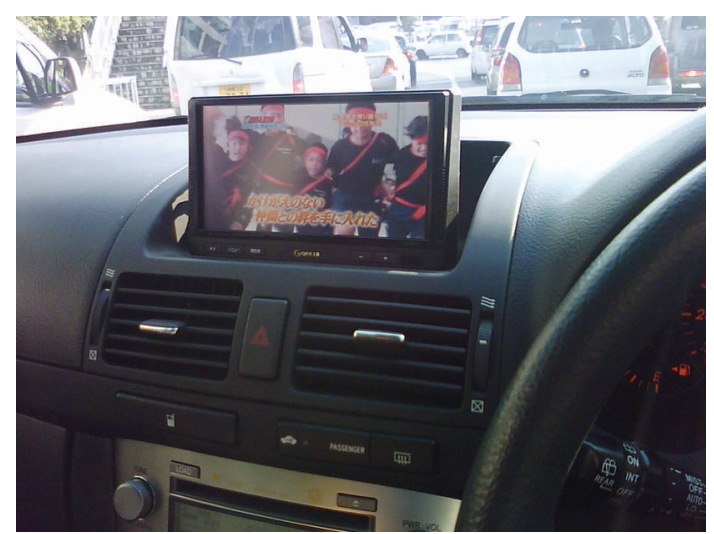

Figure 16: 2CD mode mobile TV reception demonstration.

use both front and rear antennas. 8AA has 4 front antennas and 4 rear antennas.

\section{Measurement Results}

Figure 13 shows the measurement results with typical urban 6 path Rayleigh fading (TU6) in 2CD mode. Thanks to the newly introduced circuits, the maximum Doppler performance is improved from $41 \mathrm{~Hz}$ to $67 \mathrm{~Hz}$ (1.63 times). The 1.63 times improvement corresponds to the moving speed improvement from $73 \mathrm{~km} / \mathrm{h}$ to $120 \mathrm{~km} / \mathrm{h}$ at UHF $35 \mathrm{ch}$ (605.143 MHz).

Mobile reception performance was measured in field experiments at three severe test courses in Osaka Japan. The experimental UHF channel is 13 which is broadcast from the top of Ikoma Mountain between Osaka and Nara prefecture. 64QAM, code rate of 3/4, 12-segment HDTV broadcasting service is used. The three test courses are a suburban area $50 \mathrm{~km}$ from Ikoma broadcasting station (BS), a mountain area $40 \mathrm{~km}$ from the BS, and an urban area in the other side of a hill $20 \mathrm{~km}$ from the BS. Figure 14 shows the reception rate (error free reception duration to the total experiment duration) of those test courses. The one-chip solution 4AA mode showed close performance to the two-chip solution 4CD mode.

Figure 15 shows the die micrograph and the die features are summarized in Table 5. Two pre-FFT adaptive array (AA) antennas and a post-FFT carrier diversity $(\mathrm{CD})$ combiner are integrated with an ISDB-T OFDM receiver in $90 \mathrm{~nm} 7 \mathrm{M} 1 \mathrm{P}$ CMOS process occupying $49 \mathrm{~mm}^{2}$ and dissipating $310 \mathrm{~mW}$. The two stage diversity combiners result in a logic reduction of $39 \%$ over a conventional $4 \mathrm{FFT} / \mathrm{EQs}$ carrier diversity system. The total logic size and the memory size are $18 \mathrm{M}$ gates and $18.4 \mathrm{M}$ bits, respectively. The package is a $12 \mathrm{~mm}$ square 144 pin fine pitch ball grid array.

\section{Conclusion}

The LSI integrated two pre-FFT Adaptive Array (AA) and one post-FFT carrier diversity $(\mathrm{CD})$ combiners with an ISDB-T compatible OFDM receiver in $90 \mathrm{~nm} 7 \mathrm{M} 1 \mathrm{P}$ CMOS. A 2/4/8-antenna diversity receiver can be configured. Two stage diversity methods reduce logic circuits by $39 \%$ over the 4FFT CD configuration. SPLINE interpolator and Super denoise filter circuits improve the Doppler performance by 1.63 times. This corresponds to a $73 \mathrm{~km} / \mathrm{h}$ to $120 \mathrm{~km} / \mathrm{h}$ increase at UHF $35 \mathrm{ch}$ in $2 \mathrm{CD}$ mode. The die area is $49 \mathrm{~mm}^{2}$ and the power consumption is $310 \mathrm{~mW}$. The LSI was successfully utilized in a real mobile TV system product in a Japan ISDB-T application. Figure 16 shows a $2 \mathrm{CD}$ mode mobile TV reception demonstration using the product.

\section{Acknowledgments}

The authors thank Takuya Koujiya for the field experiment support, and Kenichi Satou, Atsushi Suyama for the tuner device support, and Kunio Morimoto for module design.

\section{References}

[1] J. A. C. Bingham, "Multicarrier modulation for data transmission: an idea whose time has come," IEEE Communications Magazine, vol. 28, no. 5, pp. 5-14, 1990.

[2] S.-I. Matsuzawa, K. Sato, and K. Nishikawa, "Study of onglass mobile antennas for digital terrestrial television," IEICE Transactions on Communications, vol. E88-B, no. 7, pp. 30943096, 2005.

[3] S. Sakaguchi, M. Hori, H. Asato, et al., "An adaptive array direction control LSI for mobile digital HDTV receivers," in Proceedings of the IEEE International Conference on Consumer Electronics (ICCE '05), pp. 299-300, Las Vegas, Nev, USA, January 2005, Session: 7.4 Acquisition Systems 7.4-3.

[4] H. Asato, T. Tabata, D. H. Pham, et al., "A software-configurable adaptive array antenna system for ISDB-T reception," in Proceedings of the IEEE International Conference on Consumer Electronics (ICCE '06), pp. 463-464, Las Vegas, Nev, USA, January 2006, Session: 11.2 Signal Processing for Multiple Ant., DVB-T and DAPSK/DMT 11.2-1.

[5] D. H. Pham, T. Tabata, H. Asato, S. Hori, and T. Wada, "Joint hardware-software implementation of adaptive array antenna for ISDB-T reception," IEICE Transactions on Communications, vol. E89-B, no. 12, pp. 3215-3224, 2006. 
[6] S. Nakahara, H. Hamazumi, K. Shibuya, and M. Sasaki, "An application of diversity combination techniques to broadcasting wave relay station for ISDB-T," ITE Technical Report, vol. 25, no. 31, pp. 7-12, 2001.

[7] K. Kamiyama, H. Mizutani, H. Toma, et al., "A high-speed mobile OFDM receiver LSI with an iterative noise-reduction filter to enhance channel estimation," in Proceedings of the IEEE International Conference on Consumer Electronics (ICCE '05), pp. 193-194, Las Vegas, Nev, USA, January 2005, Session: 5.1 Digital TV Broadcast: DVB \& ISDB-T 5.1-3.

[8] M. Fujimoto and T. Hori, "Effect of antenna element characteristics on antenna pattern control of array antenna," Tech. Rep. RCS2004-177, IEICE, October 2004. 

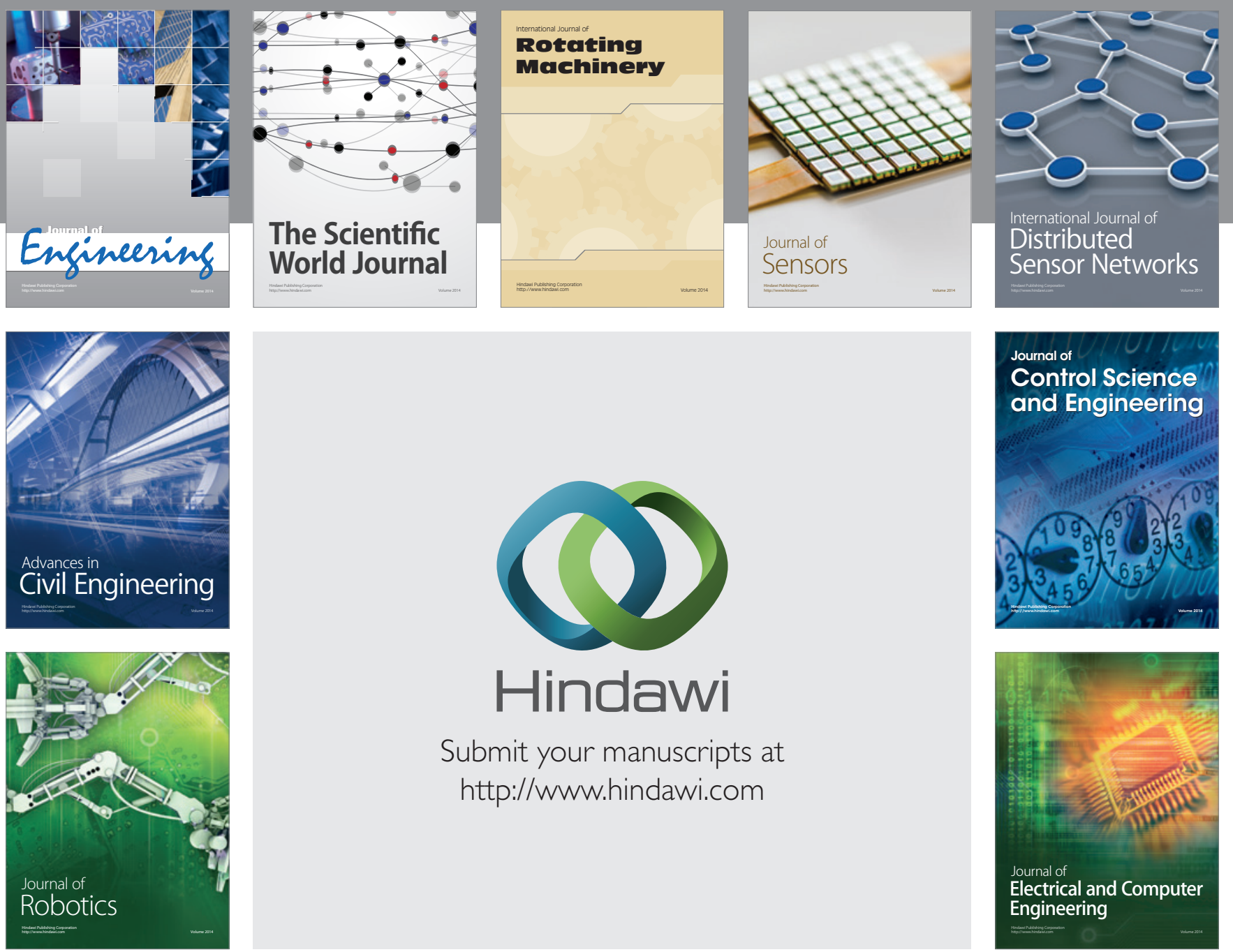

Submit your manuscripts at

http://www.hindawi.com
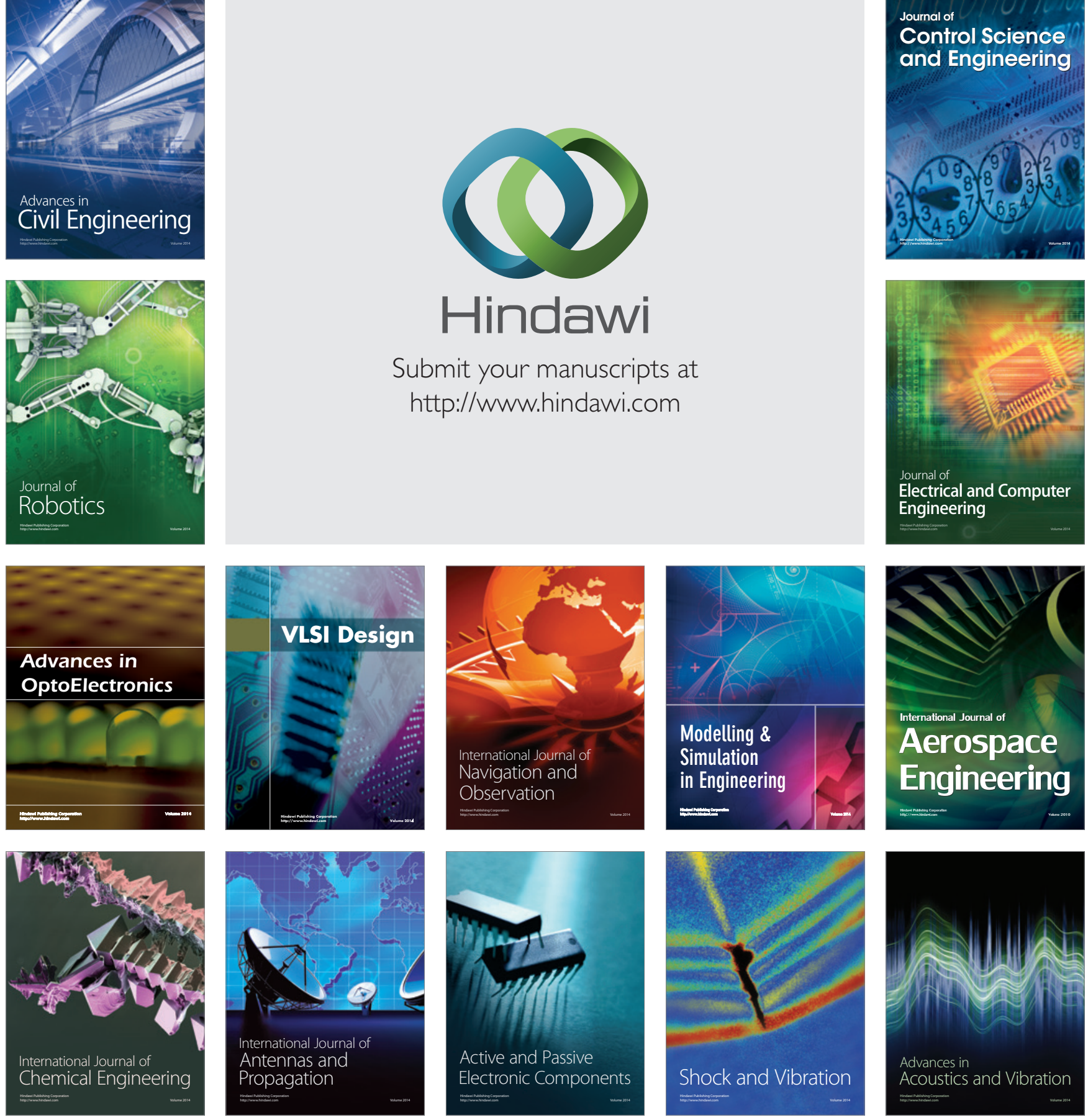